Article

\title{
Analysis of Environmental Management Characteristics Using Network Analysis of CEO Communication in the Automotive Industry
}

\author{
Yongkyu Choi ${ }^{1}$ and Keun Tae Cho ${ }^{2, *}$ \\ 1 Graduate School of Management of Technology, Sungkyunkwan University, Seoburo 2066, \\ Suwon 16419, Korea; cykriver@skku.edu \\ 2 Department of Systems Management Engineering \& Graduate School of Management of Technology, \\ Sungkyunkwan University, Seoburo 2066, Suwon 16419, Korea \\ * Correspondence: ktcho@skku.edu; Tel.: +82-031-290-7602
}

Citation: Choi, Y.; Cho, K.T. Analysis of Environmental Management Characteristics Using Network Analysis of CEO Communication in the Automotive Industry. Sustainability 2021, 13, 11987. https://doi.org/ $10.3390 /$ su132111987

Academic Editor: Carlos

Rodríguez Monroy

Received: 31 July 2021

Accepted: 26 October 2021

Published: 29 October 2021

Publisher's Note: MDPI stays neutral with regard to jurisdictional claims in published maps and institutional affiliations.

Copyright: (c) 2021 by the authors. Licensee MDPI, Basel, Switzerland. This article is an open access article distributed under the terms and conditions of the Creative Commons Attribution (CC BY) license (https:// creativecommons.org/licenses/by/ $4.0 /)$.

\begin{abstract}
CEO messages in CEO communication are becoming increasingly important. From a sustainable management perspective, it is imperative to study environmental, social, and governance messages. Previous studies on CEO messages have focused on financial analyses. In contrast, this study (1) extracted environment-related words in the CEO messages of automotive companies, (2) selected high- and low-performing automotive manufacturers based on car sales data, (3) compared environment-related keywords used by high-performing (upper group) and low-performing (lower group) companies, and (4) performed a structural interpretation of the keywords to analyze the characteristics of environmental management. A comparison between the upper and lower groups revealed that six keywords—society, electric, technology, standards, contribute, and global-were exclusive to the upper group. The six keywords exclusive to the lower group were sales, target, promote, energy, efforts, and system. Environmental keywords and eco-innovation factors were subjected to keyword-factor mapping and network analysis. Normative pressures, technology, and environmental managerial concerns were the key factors with the highest centrality. Accordingly, the environmental management characteristics of the upper-group corporations can be used as benchmarks by lower groups.
\end{abstract}

Keywords: ESG; CEO communication; environmental sustainability; network analysis; text mining; automotive industry

\section{Introduction}

CEO communication includes CEO messages, interviews, and social media [1-3]. CEO messages are one of the means of CEO communication and can be viewed as an official opinion of a company. Drawing on an earlier study that views CEO communication as an important strategic tool [1], this study analyzed the content of CEO messages in automotive companies' annual and sustainability reports to reveal their characteristics.

The message from the CEO that usually prefaces annual reports is critical to a sound corporate communication strategy [4-6]. Because messages from chief executive officers (CEOs) affect corporate management performance [7], they should represent the values, philosophy, and direction of the corporation [8]. CEOs are responsible for corporate management performance and sustainability [9], and their actions affect the performance of their organizations [10]. It can be assumed that high-performing corporations have implemented sustainable management, and it is thus important to analyze their CEO messages [8].

Environmental, social, and governance (ESG) competencies are crucial aspects of modern corporations [11]. The United Nations Environment Programme Finance Initiative (2006) [12] describes the concept of ESG as the notion of information "that ties corporate 
social and financial performance together" [13]. UN Agenda 2030 has emphasized the importance of corporate ESG information in terms of the sustainability disclosure of major public companies in Europe [11]. Corporate ESG performance (environmental impact, social responsibility, and governance) is critical due to its influence on investment decisions [14].

There is a growing need for ESG scoring methods [15]. An EU taxonomy was formulated in March 2020 to assess the environmental sustainability of the economic activities of companies [16]. The "E" (environment) in ESG is predicted to gain importance as the EU establishes new environmental standards.

Strong financial performance does not necessarily imply sound environmental management [17], and improvements in environmental impacts are not considered when assessing short-term financial performance [18]. However, environmental concerns have influenced environmental strategies in the automotive manufacturing industry [19]. Recent climate change has accelerated technological competition among global automotive companies [20]. Applying stricter regulations on the $\mathrm{CO}_{2}$ emissions of new cars and equipping 13 million cars with zero/low $\mathrm{CO}_{2}$ emissions by 2025 were discussed during the EU Summit in December 2019 [21]. Corporations that intend to maintain existing business structures are experiencing decreasing profitability [21].

CEO messages are a significant part of corporate communication strategies to shape the culture of the corporation or organization [5]. Because CEOs are accountable for formal statements, CEO letters are a useful tool for evaluating the resolution and intention of corporate leadership [22]. Accordingly, CEO messages embody the leadership, values, and attitudes of the CEO [8]. They can be useful in determining the management and vision of a corporation and are actively researched in related fields and academia [6].

Previous research on CEO letters has focused on the correlation between financial performance and CEO communications [4,23]. Moreover, text-mining techniques have been used to analyze the linguistic characteristics of CEO messages in terms of readability, sentiment score, vocabulary, etc. [22]. Safety management characteristics have also been analyzed using text mining, network analysis, and factor mapping of CEO statements [8].

In contrast to past analyses that focused on the words themselves and their characteristics, recent studies have shifted toward the integrated analysis of text and networks, enabled by the increased availability of information, technological advances in software and algorithms, and development of software packages for text analysis [24-27]. Furthermore, secondary network analysis has been performed using text-data-based network analyses and keyword-factor mapping [8]. Network analysis is useful for visualizing network structures and leveraging interactive visualization [28].

In this study, CEO messages were exported from 46 reports. Automotive manufacturers were divided into upper and lower groups based on 2019 car sales data [29], and the characteristics of the most recent CEO messages were analyzed. Using the criterion for differentiating groups in previous studies [30], the 46 manufacturers (samples) were evenly divided into 23 upper and 23 lower corporations based on car sales performance. Environment-related sentences for the upper and lower groups were extracted.

Although endogeneity concerns are common in studies [31,32] similar to the present work, we believe that a significant benefit to our setting is that the identified relation between car sales performance and environmental management characteristics is difficult to explain by reverse causality. We posit that top-performing automotive manufacturers drive environmental innovation factors from the perspective of ESG. Conversely, could environmental management characteristics be the driver of performance? Given the literature introduced previously $[17,18]$, we suspect not. Environmental concerns have influenced firms' environmental strategy factors [19]. Since all other factors can equally prevent environmental problems, environmental innovation factors should be encouraged from the perspective of ESG.

Accordingly, in this study, environment-related words with high centrality were mined from the reports of global automotive companies as a follow-up to recent studies on eco- 
innovation and its ability to enhance corporate management performance [33,34]. The results were then subjected to eco-innovation factor mapping and classification to analyze the intention and characteristics of CEO messages [8]. Fourteen major eco-innovation factors classified in a literature review [34] were used in this analysis. These factors provide a comprehensive framework for identifying the current status of environmental management.

The results of mapping environmental keywords with environmental innovation factors indicate that ESG-oriented factors are important for top companies. As the automotive industry changes, CEOs are playing an increasingly important role in adopting environmental innovation to solve problems in each ESG area and in integrating corporate strategies.

Because conducting surveys or interviews with corporate CEOs is challenging [8], this study investigates the intention and characteristics of environment-related messages in CEO communications. Because this study was conducted using current data, it presents the latest trends in the evolving automotive industry. Moreover, the environmental strategies and vision of advanced automotive corporations can be benchmarked by late movers. Finally, this research provides the key factors necessary for the sustainable management of automotive industries.

This study aimed to (1) analyze the statements of automotive company CEOs to evaluate their views and intentions by identifying the keywords of high-performing (upper group) and low-performing (lower group) corporations based on centrality analysis; (2) compare the characteristics of keywords in the existing literature to those reflected in actual management; (3) compare and analyze the upper and lower groups through keyword-factor mapping and network analysis to investigate the ultimate goal of environmental management; and (4) address environmental recommendations for more effective communication between CEOs and stakeholders.

The remainder of the paper is organized as follows. In Section 2, the existing research is investigated, and a distinction between previous work and this study is drawn. In Section 3, the text-mining techniques, network analysis, and factor mapping processes used for data collection and processing are described. In Section 4, the upper and lower groups are compared on the basis of centrality analysis, and weighted keyword lists and data visualization are presented. In Section 5, the characteristics of the keywords, trend comparison with the existing literature, and network structure are explained with examples. In Section 6, the limitations and future perspectives of this study are presented.

\section{Literature Review}

\subsection{Comparative Research Trends of CEO Messages in Upper and Lower Groups}

Research on CEO statements aims to investigate and determine the relationship between corporate messages and management performance [8]. Moreover, comparative studies between upper and lower groups can foster the growth of younger corporations [8]. Using the top 25 and bottom 25 Fortune 500 corporations, Kohut et al. [4] analyzed the technical characteristics of CEO messages, such as word count, the number of sentences, and syllables per word, and established their relationship with return on equity (ROE). Clatworthy et al. [35] studied CEO messages in the annual reports of profitable and unprofitable corporations (30 of each) and assessed the readability in each group. Highly profitable corporations discussed acquisitions and disposals, whereas unprofitable corporations discussed replacing the board of directors. Clatworthy et al. [36] discussed the relationship between corporate financial statements and the textual characteristics of CEO statements based on an analysis of the top and bottom 100 corporations. They suggested that the CEOs of low-performing companies focused more on promoting their corporate image and prospects than their current situation. Hammami [37] analyzed the annual reports of the top and bottom 20 corporations among 159 Italian companies, and their results indicated that low performers intentionally framed their messages with an excessive number of positive words. From Standard \& Poor's 500, Laskin [30] selected six corporations from each of the 10 sectors (health care, telecommunications services, etc.), resulting in a total sample of 59 companies (only five companies operating in the telecommunications 
services sector were selected), and compared the narrative strategies of the three best- and worst-performing stocks by analyzing their annual reports.

\subsection{Research Trends on Messages via Network Analysis}

An audience may have difficulty grasping the core message of long and tedious communication [8]. Tambayong et al. [38] sampled multiple news articles and analyzed their characteristics using textual network analysis. They examined changes in the political environment of Sudan by observing more than 40,000 newspaper articles (from the Sudan Tribune) written by Sudanese politicians from 2003 to 2008. Using keyword extraction, factor mapping, and network analysis, Choi et al. [8] derived safety management characteristics from the statements of construction company CEOs. Chung et al. [39] studied two presidential inauguration addresses using social network/sociopsychological textual analysis. The analysis of statements is necessary to delineate the structure, characteristics, and clarity of the message.

Hong et al. [40] utilized network analysis to structurally analyze the addresses and speeches of three 2012 presidential candidates. Their visibility and connectivity were evaluated, and the implications of the addresses were interpreted. Nam et al. [41] performed a network analysis on the promotional statements of two Korean presidential candidates. The characteristics and frequency of words were established, and differences in word choice were used to investigate promotional strategies. Based on data from the National Archives of Korea, Jung et al. [42] conducted a network analysis on the directives of three presidents. Their results confirmed that the policy directions of the presidents were linked to the correlation between their intentions and policies.

\subsection{Environmental Management Research Trends}

The scope of environmental management research includes environmental performance, environmental strategy, environmental innovation, and financial performance, and many studies are related to financial performance in particular. Cong et al. [43] targeted companies within four polluting industries (petroleum, gas, chemical, paper/utilities) among the Newsweek Green Ranking US 500. They selected two indices for environmental performance: the environmental impact score and modeled hazard population results. They concluded that the environmental disclosure scores from CEO letters were inversely proportional to their environmental performance.

Díaz-Garrido et al. [19] inferred the importance of a firm's proactive environmental strategy factors from (i) the size of the corporation, (ii) management's attitude toward the environment, and (iii) the perceived importance of stakeholders in influencing the firm's environmental practices. Kang et al. [44] surveyed Korean corporations to establish the correlation between environmental strategies and environmental performance, remarking that passive environmental strategies failed to achieve high environmental management performance.

Hojnik et al. [45] proposed that regulations, market-pull factors, environmental management systems, and cost savings are the driving factors for eco-innovation. Medeiros et al. [46] identified market, law, and regulation knowledge, inter-functional collaboration, innovationoriented learning, and R\&D investment as the major factors contributing to environmentally sustainable product innovation.

Szász et al. [18] demonstrated that improvements in environmental performance were not reflected in the short-term financial performance of automotive companies. Park et al. [17] analyzed the correlation between the environmental soundness and financial performance of Korean public companies; their results revealed that high financial performance does not necessarily imply good environmental management. Kim et al. [47] studied the relationship between environmental management and financial performance by conducting surveys on Korean corporations and found that environmental management activities negatively affected environmental and financial performance. 


\subsection{Novelty of This Study}

In previous studies, most comparisons of CEO statements between upper and lower groups were conducted from a financial perspective, primarily focusing on the characteristics or patterns of sentences or words rather than their textual relationships. The thresholds for dividing companies into upper and lower groups differed among studies, and samples were adaptively chosen to meet the need to distinguish between upper and lower groups. Moreover, previous research has utilized the text-mining method or network analysis, whereas factor mapping analyses have rarely been applied, especially within the automotive industry.

Although research has been conducted on messages from a political or safety perspective, few studies have provided an environmental perspective on the automotive industry. Several attempts have been made to study environmental management using systematic literature reviews and statistical and text-mining approaches, whereas few network analyses have been conducted on CEO statements.

To address the paucity of previous research on the above aspects, this study contributes the following to the existing literature: (1) The environmental approach was adopted to study CEO statements in the automotive industry. (2) The words used by the upper and lower groups were compared to extract keywords. (3) Data were collected using text mining, the network was analyzed, and factors were mapped and compared between the upper and lower groups. (4) Corporate environmental management was investigated using eco-innovation factors to compare the upper and lower groups' influence, structure, and characteristics. (5) Eco-innovation factors with significant and weaker influence were identified, and structurally significant factors were isolated. (6) Environment-related keywords presented in the literature were compared to the keywords emphasized by current CEOs.

\section{Materials and Methods}

\subsection{Data Collection}

The subjects of this analysis were selected from the global automotive information platform (MARKLINES). MARKLINES has been providing statistical data on automotive production/sales since 2001 and, owing to its data credibility, has been used in various studies on the automotive industry [48]. In this study, upper and lower groups of automotive manufacturers were selected based on 2019 car sales data [29], and the characteristics of their most recent CEO messages were analyzed.

The selected CEO messages met the following two criteria: messages must include an overall statement about the company and not be biased toward certain management sectors; messages must be about the company's latest management situation [8]. These CEO messages were included in introductions to annual reports and sustainability reports $[49,50]$. These reports differed in the inclusion of financial performance reporting; however, they were generally similar in all other aspects [8].

CEO messages provide economic, environmental, and social performance indicators during the year, with corresponding corporate information on the vision, strategies, and environmental leadership $[43,50]$. The messages are accessible and communicate the corporation's financial and non-financial performance, image, and identity [5]. Sustainability reports, in particular, observe the reporting guidelines provided by the global reporting initiative, which stipulates the inclusion of positive and negative aspects of the sustainable performance of corporations [51].

Because publishing reports is not a legal requirement, issued reports are inconsistent among different companies. In this study, annual reports or sustainable reports published in 2019 or 2020 were selected based on MARKLINES 2019 data. The internet homepage of each automotive company was visited, the CEO messages from annual or sustainability reports were exported, and all files were converted to .txt (text) files. This process was repeated to acquire 46 CEO messages. Although most CEO statements were available in both English and a native language, some companies only provided a Chinese version; to 
avoid potential translation errors, Chinese texts without an English version were excluded from the analysis.

In many cases, multiple corporations issued a single report owing to their governance structure (group holdings, M\&A, parent company), which we analyzed at the highest available level. For example, Peugeot, Opel, and Vauxhall issued one consolidated Peugeot Société Anonyme Group report [52,53]. The performance of other manufacturers that failed to issue separate reports was not considered because they were assumed to be part of a group.

Based on this procedure, 46 reports (CEO messages) were identified and selected for analysis. The sample comprised 21 sustainability reports, 20 annual reports, and 5 corporate social responsibility or environmental reports. Using the criterion for differentiating groups in previous studies [30], the 46 manufacturers (samples) were divided into 23 upper and 23 lower corporations based on 2019 car sales performance.

\subsection{Data Preprocessing}

CEO messages converted to text files are unstructured character data [8]. To analyze unstructured textual data using text-mining techniques, data preprocessing was required [54]. $\mathrm{R}$ software version 4.0.2 was used for data preprocessing with the tm package based on natural language processing, a frequently utilized approach in text mining [8].

First, a corpus was created from the words in a sentence [8]. Subsequently, uppercase words in the corpus were converted to lowercase words for equal treatment. Irrelevant digits and symbols, grammatical articles or prepositions ( $a$, an, of, and for), modal verbs (will), adverbs (also, now, even), and analytically meaningless words were removed [8]. Analytically meaningless words that were excluded were corporate names, such as Mazda, and automotive industry-specific words (car, cars, company, corporate, group, groups, truck, trucks, vehicle, vehicles). In addition, one, year, new, and zero were irrelevant, and order, part, and terms within phrases (such as in order to, as part of, or in terms of) were considered immaterial to the analysis.

Any sentences that included the terms environment, eco, emission, carbon, and green were consolidated into a single .txt file. Finally, TermDocumentMatrix and as.matrix were used to convert the .txt file to a 1-mode matrix, wherein rows and columns were expressed with words, and a .csv file of the dataset was generated [8].

\subsection{First Network Analysis}

In contrast to conventional text analysis, in which the occurrence of specific concepts (authors, years, subjects, etc.) is statistically analyzed, language network analysis, also referred to as network text analysis [38], is an extended content analysis technique that quantitatively analyzes the resultant network by interpreting the relationship between specific textual concepts [55]. As with general network analysis, language network analysis comprises nodes that represent actors and links denoting their relationships [56]. In language network analysis, core concepts or words are considered nodes, and their relationship corresponds to a link; however, the directionality between words is neglected [56].

In network analysis, concepts with high centralities can be captured to potentially clarify the entire text's intention or meaning and identify keywords [55]. Centrality can be quantitatively evaluated; high centrality implies that the corresponding word is located at the center of the network, is mentioned frequently, and has close connections, suggesting that it is a keyword [8]. Centrality determines the role of a specific node in its network; it is a crucial concept in network analysis [57]. The centrality value calculated for each node in the network indicates its rank relative to other nodes [55]. The software used for the centrality analysis was Gephi version 0.9.2 (open-source software with strength in visualization, used in various studies [58]).

In this study, the betweenness centrality and closeness centrality of Freeman's centrality index [59] and the eigenvector centrality proposed by Bonacich [60] were analyzed to identify keywords. Because this study measured the importance and relationships of 
words in CEO messages, the degree centrality, which simply characterizes the link between the nodes, was not analyzed [40]. Betweenness centrality measures the connection between one group and another via the connection between nodes [57]. Closeness centrality is a measure of how short the distance is from one node to others [61]. Eigenvector centrality is used to measure the importance of a node, considering the weights and centrality of the surrounding nodes [57]. Generally, when deriving keywords, the number is limited to less than 50 [57]; in this study, 43 keywords for the upper group and 44 keywords for the lower group were generated because the top 30 words were extracted on the basis of three different analyses, namely, eigenvector, betweenness, and closeness centralities, allowing for duplicates [8].

\subsection{Factor Mapping}

The keywords were obtained, allowing for duplicates, by identifying words with the 30 highest betweenness, closeness, and eigenvector centralities. Based on the centrality analysis, the words were weighted to measure the importance of the nodes as follows [57]: 3 was assigned to words exhibiting all three centralities, 2 was assigned to those with two of the three centralities, and 1 was assigned to those with only one of the three centralities [57].

After creating the list of weighted words, mapping and classification were performed with certain indicators. The eco-innovation indicators were obtained from Bossle's "Drivers and motivation for adopting eco-innovation," presented in 2016, reflecting the latest research literature trends and citations [34]. Fourteen types of factors exist: (1) regulatory pressures, (2) normative pressures, (3) cooperation, (4) expanding market, (5) technology, (6) the role of governments, (7) efficiency, (8) adoption of certifications, (9) environmental managerial concerns, (10) environmental leadership, (11) environmental culture, (12) environmental capability, (13) human resources, and (14) performance.

To enhance the objectivity of the mapping, six current employees of Korean automotive industries $(\mathrm{H}, \mathrm{K}$, and $\mathrm{S})$ with more than 10 years of experience were selected as experts, and interviews were conducted from 11 April to 10 June 2021. The sentences that included the keywords were reviewed and mapped with eco-innovation factors according to their context. Each keyword was mapped with three factors [8]. If more than four factors were mapped with a word, then the factors with the highest mapping frequency received priority; however, if the mapping frequency could not resolve the issue, three factors were selected based on consultation with experts [8], after which the factor mapping of the words was finalized.

The ultimate goal of this study was to derive the characteristics of environmental management by investigating the relationships between eco-innovation factors. Hence, the analysis of two factors in a 2-mode matrix with different rows and columns was converted to an analysis with a 1-mode matrix [62]; the MMULT and TRANSPOSE functions of Excel version 2019 were used in this process [8].

\subsection{Second Network Analysis}

In the first network analysis step (Section 3.3), all valid keywords were extracted using three centrality analyses. This was followed by an eigenvector centrality analysis to capture the key nodes of eco-innovation factors; high eigenvector centrality implies a stronger connection with surrounding nodes [63].

In other research, eigenvector centrality analysis of key nodes was conducted to find influential users in a network based on a Twitter database [64], and eigenvector centrality was used to find key nodes in an electrical grid [65]. Additionally, leadership index research on online cooperative learning was performed using eigenvector centrality to identify individuals who could play a leader role [25]. 


\subsection{Upper and Lower Group Results}

Eigenvector centrality was used to compare keyword lists derived from upper and lower groups. Based on centrality analysis, the key factors and eco-innovation factors were visualized and compared. The procedure and methodology are illustrated in Figure 1.

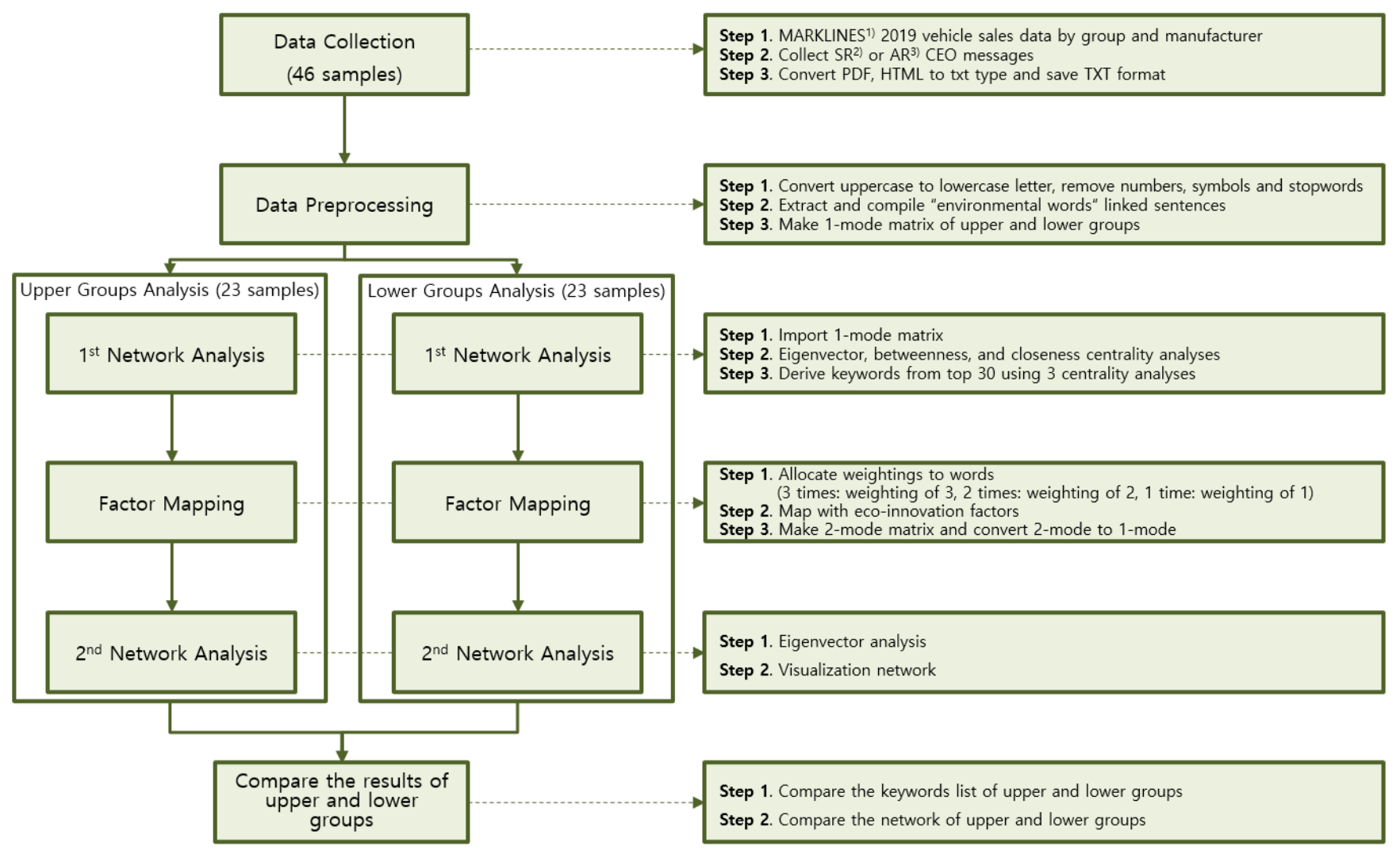

$\begin{array}{lll}\text { 1) MARKLINES: Global Automotive Information platform } & \text { 2) Sustainability Report } & \text { 3) Annual Report }\end{array}$

Figure 1. Research procedure and method.

\section{Results}

Choi et al. [8] listed the sentences of the top 100 corporations as a group. In this study, based on comparative research on upper and lower groups by Laskin [30], the frequencies of environment-related sentences and stated words were determined, and environmental management characteristics, propensities, and the environmental intentions of CEOs of the upper and lower groups were compared. Because some automotive companies did not issue SRs/ARs and multiple manufacturers published one report due to their governance structure, 23 sample reports were retrieved from each group (upper and lower groups) to extract the CEO messages. The performance of manufacturers that belong to such groups but did not issue separate reports was excluded, and these companies were assumed to exist as a group. As shown in Figure 2, 131 and 92 sentences were extracted for the upper and lower groups, respectively.

\subsection{Word-Based Network Analysis}

Each of the three centrality analyses resulted in 30 keywords, which are listed in descending order of centrality (see Table 1). The 131 sentences in the upper group included environment, eco, emission, carbon, or green. The number of unique keywords is 43 , of which more than half (1-18 in ranking) exhibit high centralities in all three fields. In particular, business, society, sustainable, electric, change, development, and global are among the important keywords with the top 10 centrality scores. 
131 cases, 59\%

92 cases, $41 \%$

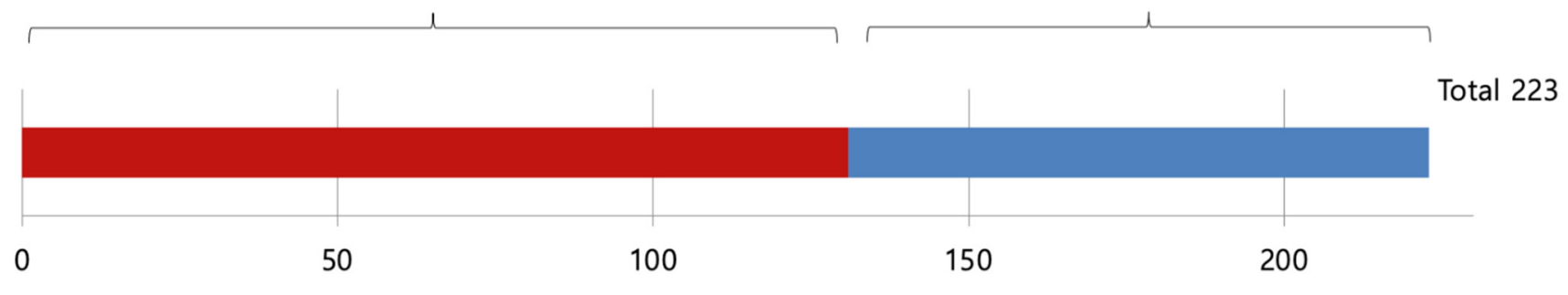

Upper group (top 23 samples) - Lower group (lowest 23 samples)

Figure 2. Distribution of sentences with environment-related words.

Table 1. Centrality analysis results for extracted words (upper group).

\begin{tabular}{|c|c|c|c|c|c|c|}
\hline Ranking & Word & $\begin{array}{l}\text { Eigenvector } \\
\text { Centrality }\end{array}$ & Word & $\begin{array}{l}\text { Betweenness } \\
\text { Centrality }\end{array}$ & Word & $\begin{array}{l}\text { Closeness } \\
\text { Centrality }\end{array}$ \\
\hline 1 & business & 1 & business & $40,138.83$ & business & 0.562162 \\
\hline 2 & society & 0.81993 & electric & $31,163.87$ & electric & 0.544186 \\
\hline 3 & sustainable & 0.762716 & society & $24,448.53$ & society & 0.53886 \\
\hline 4 & electric & 0.719486 & sustainable & $23,656.04$ & sustainable & 0.535776 \\
\hline 5 & change & 0.700717 & change & $21,688.3$ & change & 0.527324 \\
\hline 6 & development & 0.655569 & development & $13,247.06$ & technology & 0.520289 \\
\hline 7 & technology & 0.612013 & target & $11,945.14$ & development & 0.516842 \\
\hline 8 & standards & 0.574234 & standards & $11,780.54$ & mobility & 0.512035 \\
\hline 9 & contribute & 0.532065 & global & $11,577.81$ & future & 0.510082 \\
\hline 10 & global & 0.512255 & future & $10,707.42$ & global & 0.508696 \\
\hline 11 & efforts & 0.511333 & technology & $10,690.06$ & target & 0.504854 \\
\hline 12 & target & 0.481633 & mobility & 9270.132 & products & 0.501608 \\
\hline 13 & mobility & 0.46492 & products & 8811.865 & contribute & 0.499733 \\
\hline 14 & social & 0.462696 & reduce & 8304.305 & activities & 0.496552 \\
\hline 15 & products & 0.413565 & economic & 7872.768 & social & 0.494453 \\
\hline 16 & realize & 0.408677 & create & 7668.187 & aim & 0.494192 \\
\hline 17 & activities & 0.40855 & partners & 7117.243 & efforts & 0.491339 \\
\hline 18 & future & 0.400309 & contribute & 6878.668 & reduce & 0.491081 \\
\hline 19 & vision & 0.392664 & production & 5392.069 & vision & 0.488773 \\
\hline 20 & national & 0.389468 & social & 5193.366 & working & 0.488008 \\
\hline 21 & reduce & 0.381036 & efforts & 4914.454 & standards & 0.484974 \\
\hline 22 & energy & 0.375994 & fleet & 4862.524 & set & 0.480987 \\
\hline 23 & opportunity & 0.375453 & world & 4848.27 & fields & 0.479508 \\
\hline 24 & markets & 0.369755 & markets & 3777.989 & long-term & 0.477795 \\
\hline 25 & make & 0.366018 & based & 3770.677 & use & 0.477064 \\
\hline 26 & taking & 0.361974 & activities & 3707.693 & based & 0.475852 \\
\hline 27 & focusing & 0.35865 & aim & 3650.163 & make & 0.475368 \\
\hline 28 & based & 0.349465 & make & 3646.222 & world & 0.474164 \\
\hline 29 & set & 0.346039 & way & 3467.902 & growth & 0.473684 \\
\hline 30 & economic & 0.334765 & energy & 3132.735 & issues & 0.47225 \\
\hline
\end{tabular}

In contrast, target has high betweenness centrality but low eigenvector and closeness centralities. Similarly, the words energy, economic, and markets are relevant for only eigenvector and betweenness centralities, while the words vision and set are relevant for only eigenvector and closeness centralities. The words world and aim are relevant for only betweenness and closeness centralities. In contrast, the words realize, national, opportunity, taking, focusing, use, long-term, fields, issues, working, growth, partners, create, way, production, and fleet have high scores for only one of the three centrality indexes.

For the lower group, 92 sentences included environment, eco, emission, carbon, or green. Each of the three centrality analyses resulted in 30 keywords, which are listed in descending order of centrality (see Table 2). In total, 44 unique keywords were identified. All three centralities are high for most of the first 12 words. 
Table 2. Centrality analysis results for extracted words (lower group).

\begin{tabular}{|c|c|c|c|c|c|c|}
\hline Ranking & Word & $\begin{array}{l}\text { Eigenvector } \\
\text { Centrality }\end{array}$ & Word & $\begin{array}{l}\text { Betweenness } \\
\text { Centrality }\end{array}$ & Word & $\begin{array}{l}\text { Closeness } \\
\text { Centrality }\end{array}$ \\
\hline 1 & development & 1 & business & $24,354.23$ & development & 0.58216 \\
\hline 2 & business & 0.832196 & development & $23,537.12$ & business & 0.571805 \\
\hline 3 & sustainable & 0.715153 & sustainable & $17,619.37$ & change & 0.552514 \\
\hline 4 & sales & 0.63689 & electric & $17,125.19$ & sustainable & 0.551111 \\
\hline 5 & change & 0.629479 & change & $15,892.82$ & sales & 0.536465 \\
\hline 6 & target & 0.592731 & energy & 9703.619 & energy & 0.535802 \\
\hline 7 & promote & 0.589085 & reduce & 9630.149 & reduce & 0.534154 \\
\hline 8 & energy & 0.583233 & products & 9104.493 & promote & 0.532189 \\
\hline 9 & efforts & 0.580277 & target & 7776.395 & electric & 0.528624 \\
\hline 10 & system & 0.516936 & standards & 7701.535 & products & 0.528624 \\
\hline 11 & make & 0.512959 & global & 7222.901 & target & 0.528302 \\
\hline 12 & goals & 0.512866 & sales & 6654.878 & efforts & 0.527019 \\
\hline 13 & structure & 0.506713 & range & 5957.978 & range & 0.521321 \\
\hline 14 & reduce & 0.49768 & system & 5334.649 & make & 0.518519 \\
\hline 15 & brands & 0.488883 & market & 5138.079 & global & 0.5179 \\
\hline 16 & transition & 0.467718 & economic & 4504.20792 & goals & 0.511491 \\
\hline 17 & focus & 0.463481 & promote & 4503.72214 & world & 0.51119 \\
\hline 18 & organization & 0.456703 & safety & 4156.78044 & value & 0.510588 \\
\hline 19 & products & 0.453669 & future & 4019.39735 & future & 0.509988 \\
\hline 20 & industry & 0.448368 & make & 3934.73312 & system & 0.509689 \\
\hline 21 & value & 0.430533 & focus & 3592.93861 & structure & 0.50939 \\
\hline 22 & intelligent & 0.426761 & value & 3542.1626 & safety & 0.508792 \\
\hline 23 & create & 0.408406 & world & 3500.22475 & focus & 0.506122 \\
\hline 24 & safety & 0.400915 & goals & 3409.76804 & create & 0.505533 \\
\hline 25 & world & 0.392738 & efforts & 3372.61759 & brands & 0.504358 \\
\hline 26 & strategic & 0.392322 & impact & 3157.09993 & transition & 0.502897 \\
\hline 27 & passenger & 0.385474 & production & 3095.25634 & growth & 0.501155 \\
\hline 28 & policies & 0.379459 & commercial & 3068.56056 & strategic & 0.500866 \\
\hline 29 & production & 0.376875 & challenge & 2948.80747 & reducing & 0.500577 \\
\hline 30 & premium & 0.370661 & technology & 2829.09344 & customers & 0.500288 \\
\hline
\end{tabular}

Efforts and system have high eigenvector and closeness centralities; however, their betweenness centrality is low. In addition, production only exhibits high eigenvector and betweenness centralities, and structure, brands, transition, create, and strategic only have high eigenvector and closeness centralities. For future, global, range, and electric, only betweenness and closeness centralities are high. Organization, industry, intelligence, passenger, policies, premium, growth, commercial, customers, standards, challenge, reducing, technology, economic, impact, and market have only one high centrality value among the three.

\subsection{Keyword Weightings}

For the upper group, 43 keywords were weighted based on the centrality analysis: words with centralities in the top 30 in all three categories, two categories, or only one category were assigned weightings of 3,2 , and 1, respectively [8]. Generally, words with high centrality rankings received a weighting of 3 , whereas those with low centrality rankings received a weighting of 1 [8] (see Table 3 for a summary). A weighting of 3 was assigned to 20 words, including society, electric, and standards, and a weighting of 2 was assigned to 7 words, including economic, mobility, and structure. Finally, 16 words, including focusing, long-term, and growth, received a weighting of 1 . 
Table 3. Weighted words classified based on the results of centrality analysis (upper group).

\begin{tabular}{cl}
\hline Cluster & \multicolumn{1}{c}{ Word } \\
\hline Weighting: 3 & $\begin{array}{l}\text { business, society, sustainable, electric, change, development, } \\
\text { technology, standards, contribute, global, efforts, target, mobility, } \\
\text { social, products, activities, future } \\
\text { reduce, make, based }\end{array}$ \\
\hline Weighting: 2 & vision, energy, markets, set, economic, aim, world \\
\hline Weighting: 1 & $\begin{array}{l}\text { realize, national, opportunity, taking, focusing, use, } \\
\text { long-term, fields, issues, working, growth, partners, } \\
\text { create, way, production, fleet }\end{array}$ \\
\hline
\end{tabular}

For the lower group, 44 words were weighted based on the centrality analysis. The words with centralities in the top 30 in three, two, or only one category received weightings of 3,2 , and 1, respectively [8]. Generally, words with high centrality rankings received a weighting of 3 , whereas those with low centrality rankings received a weighting of 1 [8] (summarized results in Table 4). A weighting of 3 was assigned to 18 words, including sales, promote, and efforts. A weighting of 2 was allocated to 10 words, including structure, brands, and transition, and a weighting of 1 was allocated to 16 words, such as industry, policies, and market.

Table 4. Weighted words classified based on the results of centrality analysis (lower group).

\begin{tabular}{cl}
\hline Cluster & \multicolumn{1}{c}{ Word } \\
\hline Weighting: 3 & $\begin{array}{l}\text { development, business, sustainable, sales, change, target, } \\
\text { promote, energy, efforts, system, make, goals, reduce, } \\
\text { focus, products, value, safety, world }\end{array}$ \\
\hline Weighting: 2 & $\begin{array}{l}\text { structure, brands, transition, create, strategic, } \\
\text { production, future, global, range, electric }\end{array}$ \\
\hline Weighting: 1 & $\begin{array}{l}\text { organization, industry, intelligent, passenger, policies } \\
\text { premium, growth, commercial, customers, standards } \\
\text { challenge, reducing, technology, economic, impact, market }\end{array}$ \\
\hline
\end{tabular}

\subsection{Mapping with Eco-Innovation Factors}

For the upper group, the mapping results between words with weightings of 3,2, and 1 and eco-innovation indicators are shown in Table 5, Table 6, and Table 7, respectively.

The normative pressure factor was mapped 31 times, the term environmental managerial concerns was mapped 24 times, and technology was mapped 20 times. Regulatory pressures, normative pressures, expanding market, and technology factors were mapped multiple times, and the remaining factors were mapped between 1 and 10 times. All factors were mapped.

Words with a weighting of 3 exhibited high mapping rates with the factors normative pressures, technology, and environmental managerial concerns, and words with a weighting of 2 had high mapping rates with the normative pressure factor. Normative pressures, technology, and environmental managerial concerns had high mapping rates with words with a weighting of 1 .

For the lower group, the mapping results between the weighted words and the ecoinnovation indicators are shown in Table 8 (weighting of 3), Table 9 (weighting of 2), and Table 10 (weighting of 1 ). 
Table 5. Mapping results of eco-innovation factors and words with a weighting of 3 (upper group).

\begin{tabular}{|c|c|c|c|c|c|c|c|c|c|c|c|c|c|c|}
\hline Word & A & B & $\mathrm{C}$ & D & $\mathbf{E}$ & $\mathbf{F}$ & G & $\mathbf{H}$ & I & $\mathbf{J}$ & $\mathbf{K}$ & $\mathbf{L}$ & $\mathbf{M}$ & $\mathbf{N}$ \\
\hline business & & & & 0 & 0 & & & & 0 & & & & & \\
\hline society & & o & & & & & & & 0 & & & & $\circ$ & \\
\hline sustainable & & ○ & & & o & & & & o & & & & & \\
\hline electric & & ○ & $\circ$ & & ○ & & & & & & & & & \\
\hline change & & 0 & & & 0 & & & & & & 0 & & & \\
\hline development & & ○ & ○ & & o & & & & & & & & & \\
\hline technology & & 0 & & & 0 & & & & 0 & & & & & \\
\hline standards & ○ & o & & & & & & & o & & & & & \\
\hline contribute & & ○ & & & ○ & & & & ○ & & & & & \\
\hline global & & o & & & & & & & ○ & & $\circ$ & & & \\
\hline efforts & & ○ & & & & & & & & & $\circ$ & ○ & & \\
\hline target & & & ○ & & & & & & o & o & & & & \\
\hline mobility & & & & 0 & & & & & 0 & & & 0 & & \\
\hline social & & 0 & & & & & & & 0 & & & & o & \\
\hline products & & & & $\circ$ & ○ & & & & ० & & & & & \\
\hline activities & & & & & o & & & & $\circ$ & & & ० & & \\
\hline future & & $\circ$ & & & o & & & & ○ & & & & & \\
\hline reduce & $\circ$ & ○ & & & & & $\circ$ & & & & & & & \\
\hline make & & 0 & & & 0 & & & & & & & & 0 & \\
\hline based & & 0 & & & & & & & 0 & & 0 & & & \\
\hline
\end{tabular}

A, regulatory pressures; $\mathrm{B}$, normative pressures; $\mathrm{C}$, cooperation; $\mathrm{D}$, expanding market; $\mathrm{E}$, technology; $\mathrm{F}$, the role of governments; $\mathrm{G}$, efficiency; $\mathrm{H}$, adoption of certifications; I, environmental managerial concerns; J, environmental leadership; K, environmental culture; L, environmental capability; $\mathrm{M}$, human resources; $\mathrm{N}$, performance.

Table 6. Mapping results of eco-innovation factors and words with a weighting of 2 (upper group).

\begin{tabular}{|c|c|c|c|c|c|c|c|c|c|c|c|c|c|c|}
\hline Word & A & B & C & D & $\mathbf{E}$ & $\mathbf{F}$ & G & $\mathbf{H}$ & I & $\mathbf{J}$ & $\mathbf{K}$ & $\mathbf{L}$ & $\mathbf{M}$ & $\mathbf{N}$ \\
\hline vision & & 0 & & & & & & & 0 & 0 & & & & \\
\hline energy & $\circ$ & ○ & & $\circ$ & & & & & & & & & & \\
\hline markets & & & o & & & & & & $\circ$ & & & & & ० \\
\hline set & & ० & & & & & & & 0 & & o & & & \\
\hline economic & & 0 & & & & & & & & & & 0 & 0 & \\
\hline aim & & o & 0 & & & & & & & & 0 & & & \\
\hline world & & 0 & 0 & o & & & & & & & & & & \\
\hline
\end{tabular}

A, regulatory pressures; $\mathrm{B}$, normative pressures; $\mathrm{C}$, cooperation; $\mathrm{D}$, expanding market; $\mathrm{E}$, technology; $\mathrm{F}$, the role of governments; $\mathrm{G}$, efficiency; $\mathrm{H}$, adoption of certifications; I, environmental managerial concerns; J, environmental leadership; $K$, environmental culture; $\mathrm{L}$, environmental capability; $\mathrm{M}$, human resources; $\mathrm{N}$, performance.

Table 7. Mapping results of eco-innovation factors and words with a weighting of 1 (upper group).

\begin{tabular}{|c|c|c|c|c|c|c|c|c|c|c|c|c|c|c|}
\hline Word & A & B & $\mathrm{C}$ & D & E & $\mathbf{F}$ & G & $\mathbf{H}$ & I & $\mathbf{J}$ & $\mathbf{K}$ & L & $\mathbf{M}$ & $\mathbf{N}$ \\
\hline realize & & 0 & & & 0 & 0 & & & & & & & & \\
\hline national & $\circ$ & & & & & ० & & & ○ & & & & & \\
\hline opportunity & $\circ$ & & & $\circ$ & & ○ & & & & & & & & \\
\hline taking & & & & ○ & o & & & O & & & & & & \\
\hline focusing & & ○ & & o & o & & & & & & & & & \\
\hline use & & ○ & & & o & & & & o & & & & & \\
\hline long-term & & & & & & & & & ○ & o & o & & & \\
\hline fields & & o & & & o & & & & ○ & & & & & \\
\hline issues & & ○ & & & & & & & ○ & ○ & & & & \\
\hline working & & o & ० & & & ० & & & & & & & & \\
\hline growth & & ○ & & & & & & & ○ & & o & & & \\
\hline partners & & o & ○ & & o & & & & & & & & & \\
\hline create & & $\circ$ & $\circ$ & & ○ & & & & & & & & & \\
\hline way & & ○ & & & & & & & & & o & 0 & & \\
\hline production & & & & & o & & & & 0 & & o & & & \\
\hline fleet & & & & ० & ० & & & & & & & o & & \\
\hline
\end{tabular}

A, regulatory pressures; $\mathrm{B}$, normative pressures; $\mathrm{C}$, cooperation; $\mathrm{D}$, expanding market; $\mathrm{E}$, technology; $\mathrm{F}$, the role of governments; $\mathrm{G}$, efficiency; $\mathrm{H}$, adoption of certifications; I, environmental managerial concerns; J, environmental leadership; K, environmental culture; L, environmental capability; $\mathrm{M}$, human resources; $\mathrm{N}$, performance. 
Table 8. Mapping results of eco-innovation factors and words with a weighting of 3 (lower group).

\begin{tabular}{|c|c|c|c|c|c|c|c|c|c|c|c|c|c|c|}
\hline Word & $\mathbf{A}$ & $\bar{B}$ & $\mathrm{C}$ & $\bar{D}$ & $\bar{E}$ & $\mathbf{F}$ & $\bar{G}$ & $\mathbf{H}$ & I & $\bar{J}$ & $\mathbf{K}$ & $\mathbf{L}$ & $\mathbf{M}$ & $\overline{\mathbf{N}}$ \\
\hline development & & & & & & 0 & 0 & & & & & & & o \\
\hline business & & & & & & & 0 & & & & & 0 & & 0 \\
\hline sustainable & & 0 & & & & & 0 & & & & & & & o \\
\hline sales & & & & & & & 0 & & & o & & & & o \\
\hline change & & & & & & & & O & & & & & 0 & o \\
\hline target & & & o & & & & ० & & & & & & & o \\
\hline promote & & & o & & & & o & & & & & & & ○ \\
\hline energy & 0 & & & & & 0 & & & & & & & & o \\
\hline efforts & & 0 & & & & & 0 & & & & 0 & & & \\
\hline system & & & & & & & O & & & & & o & & ○ \\
\hline make & & & & & & & o & & & & & o & & o \\
\hline goals & & & & & & & & & o & & ○ & & & ○ \\
\hline reduce & & & & & & & 0 & & & & & 0 & & 0 \\
\hline focus & o & & & & & & 0 & & & & & & & o \\
\hline products & o & & 0 & & & o & & & & & & & & \\
\hline value & & & & & & & ० & & & & & 0 & & 0 \\
\hline safety & & & & & ○ & & & & o & & o & & & \\
\hline world & o & & & & & o & & & & & & o & & \\
\hline
\end{tabular}

A, regulatory pressures; $\mathrm{B}$, normative pressures; $\mathrm{C}$, cooperation; $\mathrm{D}$, expanding market; $\mathrm{E}$, technology; $\mathrm{F}$, the role of governments; $\mathrm{G}$, efficiency; $\mathrm{H}$, adoption of certifications; I, environmental managerial concerns; J, environmental leadership; K, environmental culture; $\mathrm{L}$, environmental capability; $\mathrm{M}$, human resources; $\mathrm{N}$, performance.

Table 9. Mapping results of eco-innovation factors and words with a weighting of 2 (lower group).

\begin{tabular}{|c|c|c|c|c|c|c|c|c|c|c|c|c|c|c|}
\hline Word & $\mathbf{A}$ & B & $\mathrm{C}$ & D & E & F & G & $\mathbf{H}$ & I & $\mathbf{J}$ & $\mathbf{K}$ & $\mathbf{L}$ & $\mathbf{M}$ & $\mathbf{N}$ \\
\hline structure & $\circ$ & & & & & & ० & & & & & ० & & \\
\hline brands & & & & & & & ० & & & & & o & & ○ \\
\hline transition & & & & & & & $\circ$ & & & & & O & & o \\
\hline create & & & & & & & o & & & o & & & & o \\
\hline strategic & & & & & & & o & & & & & o & & ○ \\
\hline production & & & & $\circ$ & $\circ$ & & & & & & & & & ○ \\
\hline future & & o & & & & & o & & & & & & & ○ \\
\hline global & & & & $\circ$ & & $\circ$ & & & & & & & & ○ \\
\hline range & o & & & & & o & & & & & & o & & \\
\hline electric & & & 0 & & 0 & & & & & & & O & & \\
\hline
\end{tabular}

$\mathrm{A}$, regulatory pressures; $\mathrm{B}$, normative pressures; $\mathrm{C}$, cooperation; $\mathrm{D}$, expanding market; $\mathrm{E}$, technology; $\mathrm{F}$, the role of governments; $\mathrm{G}$, efficiency; $\mathrm{H}$, adoption of certifications; I, environmental managerial concerns; J, environmental leadership; K, environmental culture; $\mathrm{L}$, environmental capability; $\mathrm{M}$, human resources; $\mathrm{N}$, performance.

Table 10. Mapping results of eco-innovation factors and words with a weighting of 1 (lower group).

\begin{tabular}{|c|c|c|c|c|c|c|c|c|c|c|c|c|c|c|}
\hline Word & A & B & C & D & E & F & G & $\mathbf{H}$ & I & $\mathbf{J}$ & $\mathbf{K}$ & $\mathbf{L}$ & $\mathbf{M}$ & $\mathbf{N}$ \\
\hline organization & & & & & & & O & & & & & ○ & & ○ \\
\hline industry & & & & & & & o & & & & & ○ & & ○ \\
\hline intelligent & & & & & & & o & & & & & ○ & & $\circ$ \\
\hline passenger & & & & & & & ○ & & & & & ○ & & $\circ$ \\
\hline policies & ○ & & & & & o & o & & & & & & & \\
\hline premium & & & & & & & O & & & & & ○ & & o \\
\hline growth & & & & & & 0 & o & & & & & & & ○ \\
\hline commercial & & & & & & & & & & $\circ$ & & 0 & & ○ \\
\hline customers & 0 & & & & & & & & & $\circ$ & & ○ & & \\
\hline standards & ० & & & & & ○ & & $\circ$ & & & & & & \\
\hline challenge & & & & & o & o & & & & & & 0 & & \\
\hline reducing & & & & & & & o & & & ○ & & ○ & & \\
\hline technology & $\circ$ & & & & & ○ & & & & ○ & & & & \\
\hline economic & o & & & & & ० & & & & & & & & o \\
\hline impact & & & $\circ$ & & & & o & & & & & & & ० \\
\hline market & o & & & & & & o & & & & & & & ○ \\
\hline
\end{tabular}

A, regulatory pressures; $\mathrm{B}$, normative pressures; $\mathrm{C}$, cooperation; $\mathrm{D}$, expanding market; $\mathrm{E}$, technology; $\mathrm{F}$, the role of governments; $\mathrm{G}$, efficiency; $\mathrm{H}$, adoption of certifications; I, environmental managerial concerns; J, environmental leadership; K, environmental culture; L, environmental capability; $\mathrm{M}$, human resources; N, performance. 
The performance factor was mapped 31 times, efficiency was mapped 28 times, environmental capability was mapped 21 times, and regulatory pressures and the role of governments were mapped 12 times. The remaining factors were mapped 1-6 times, and all factors were mapped.

Efficiency and performance were frequently mapped with words assigned a weighting of 3, and efficiency, environmental capability, and performance were frequently mapped with words assigned a weighting of 2. Regulatory pressures, the role of governments, efficiency, environmental capability, and performance showed high mapping rates with words with a weighting of 1 .

\subsection{Network Visualization}

After mapping words with eco-innovation factors, eigenvector centrality analysis was performed to identify the relationships among factors, after which the network was visualized [66]. The network based on the eigenvector centrality analysis of the upper group is shown in Figure 3. The three key nodes, indicated in red and grouped near the center, are normative pressures, environmental managerial concerns, and technology. Efficiency, adoption of certifications, and performance are the nodes farthest from the center.

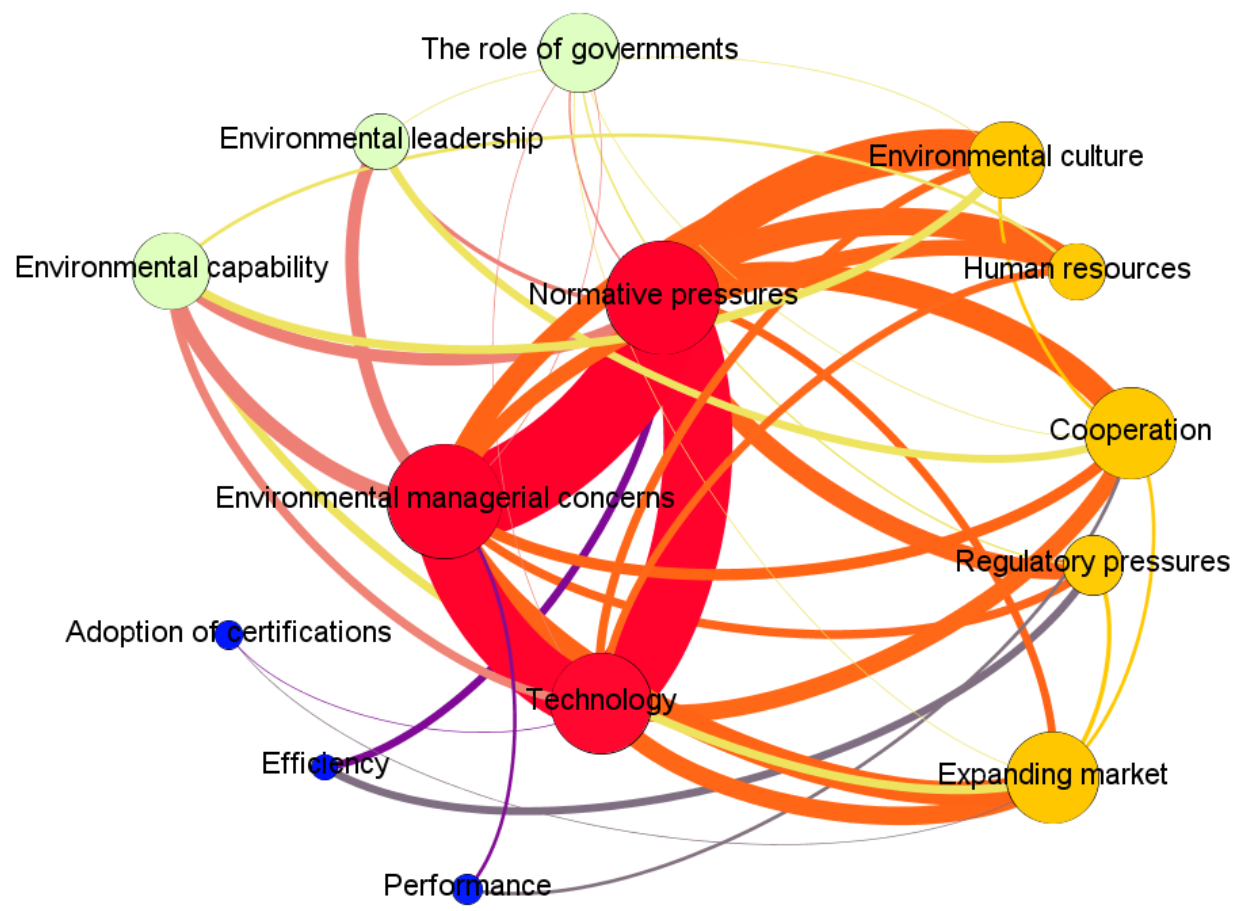

Figure 3. Network visualization of the characteristics of environmental management (upper group).

The structural relationship formed by the three words indicates strong connections between normative pressures, environmental managerial concerns, and technology. The normative pressures node has strong connections with environmental culture, human resources, cooperation, and regulatory pressures. The environmental managerial concerns node has a strong connection with environmental culture, human resources, and expanding market. Technology has a strong connection with expanding market and cooperation. Efficiency, which has the lowest eigenvector centrality, is connected to regulatory pressures and normative pressures.

The network formed based on the eigenvector centrality analysis of the lower group is shown in Figure 4. The two key nodes-performance and the role of governments-are located near the center and marked in red. The structural relationships formed by the key nodes indicate that performance and efficiency have strong connections to environmental capability, regulatory pressures, and cooperation, and the role of governments is strongly connected to regulatory pressures, efficiency, environmental capability, and cooperation. Human 
resources, which has the lowest eigenvector centrality, is connected to adoption of certifications and performance.

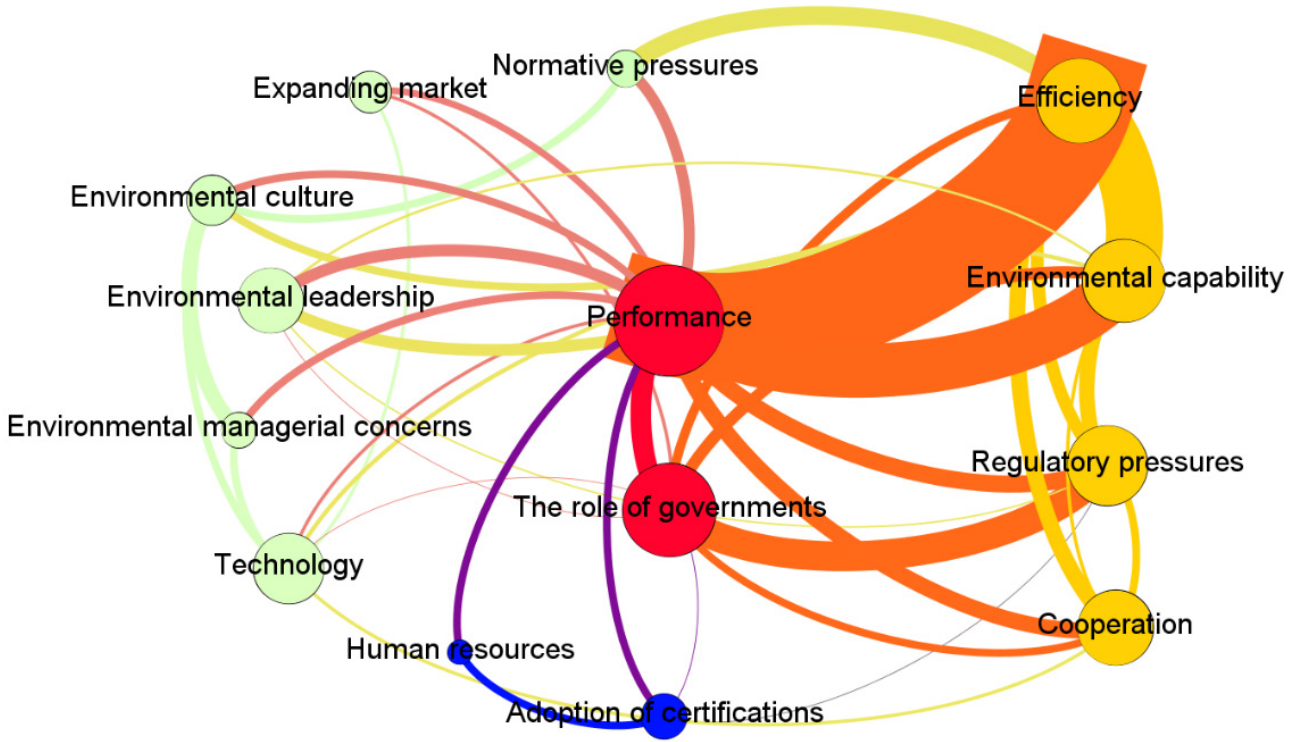

Figure 4. Network visualization of the characteristics of environmental management (lower group).

\subsection{Comparing the Upper and Lower Groups}

The network analysis in Section 4.1 revealed 43 words in the upper group and 44 in the lower group. For both groups, the top 10 keywords were identified using their eigenvector centrality scores [40].

The top 10 words in the upper and lower groups are shown in Figure 5. The keywords exclusive to the upper group are society, electric, technology, standards, contribute, and global. The keywords exclusive to the lower group are sales, target, promote, energy, efforts, and system. Four words-business, sustainable, change, and development-are common to both groups. Accordingly, society, electric, technology, standards, contribute, and global are the keywords of the upper group.

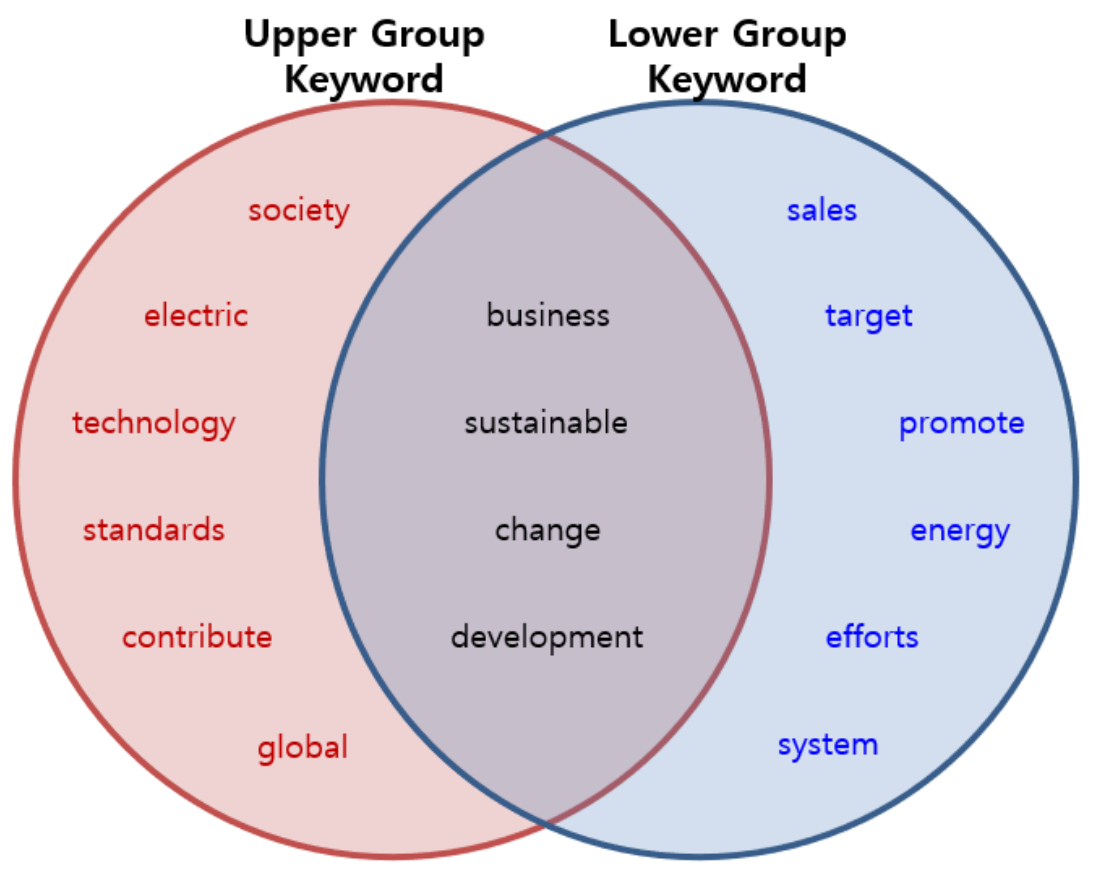

Figure 5. Comparison of top 10 keywords: upper and lower groups. 
The results of eco-innovation factor mapping for the upper and lower groups are shown in Figure 6. The key factors of the upper group are normative pressures, environmental managerial concerns, and technology, and those of the lower group are performance and the role of governments. Among the factors with high eigenvector centrality [40], those with values greater than or equal to 0.8 are considered key factors-normative pressures, environmental managerial concerns, and technology.

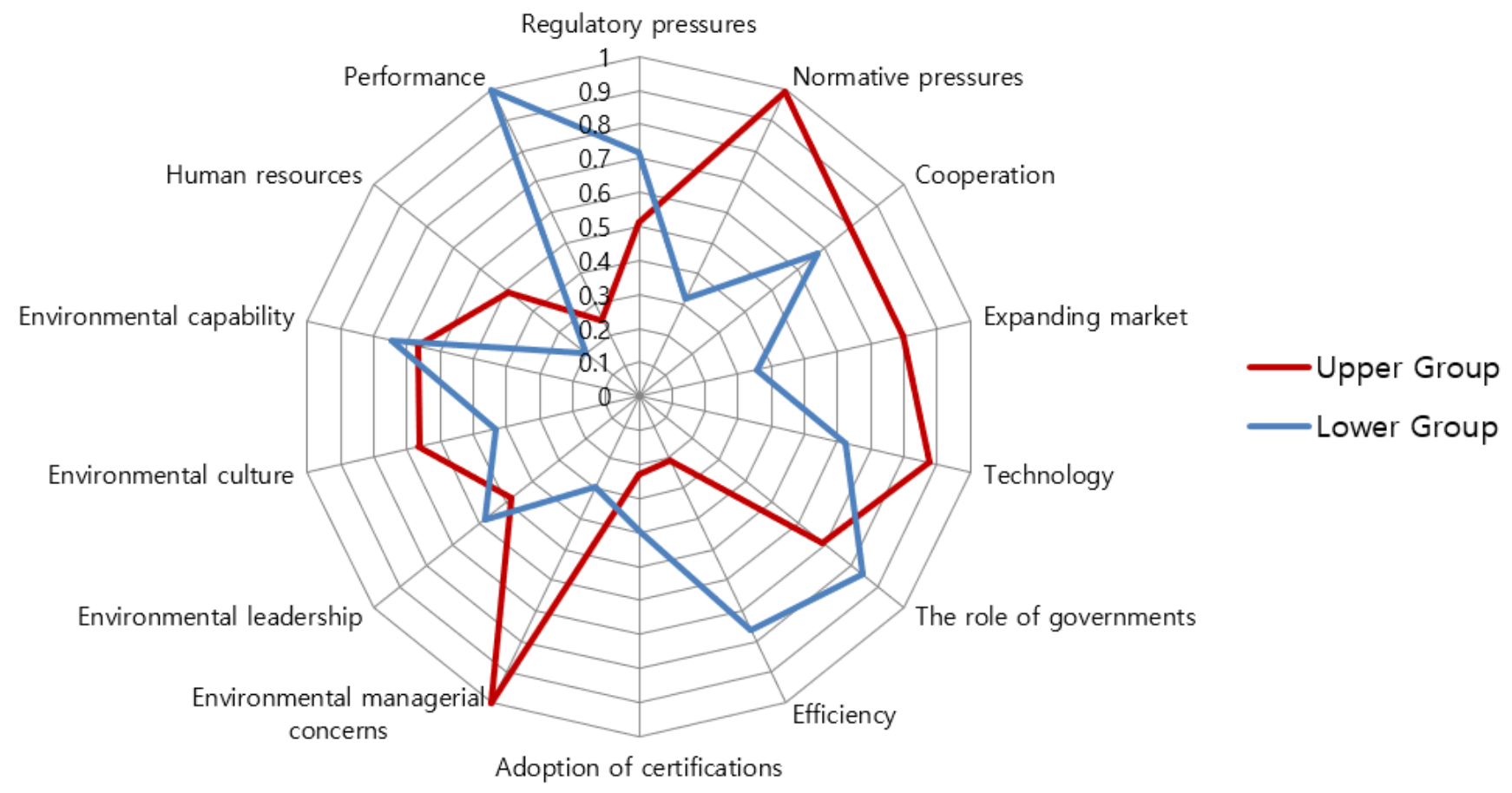

Figure 6. Network visualization of the characteristics of environmental management.

\section{Discussion}

A CEO message conveys a corporation's vision to shareholders, customers, and employees [6]. The CEO message reflects corporate strategies and insists on the originality of one's own practices, differentiating the company from its competitors [6]. Therefore, a CEO message is the most fundamental tool for CEO communication to implement a company's strategies and accomplish its aims. The sustainable growth of companies is becoming a major topic, and it has been found that CEO messages are related to the ESG (environmental, social, and governance) performance of companies [67]. ESG is a competitive factor of modern firms, and an ESG-oriented perspective for competitive advantage leads to differentiated performance among companies [11].

This study comparatively analyzed the differences in the CEO message characteristics of high- and low-performing automotive manufacturers based on car sales data. For the analysis, the sentences containing environment-related words in the CEO messages of the high-performing automotive manufacturers were checked to consolidate the sentences into a single .txt file. The sentences of low-performing automotive manufacturers were consolidated in the same way as those of the high-performing automotive manufacturers. The keywords were extracted using the $\mathrm{R}$ software, and a network analysis was conducted using Gephi software. The 14 factors of eco-innovation were used to analyze the differences in CEO message characteristics of high- and low-performing automotive manufacturers. The extracted keywords were mapped to identify the factors to which they belonged, and environmental management characteristics were determined through eigenvector centrality $[8,60]$. 


\subsection{Comparison of the Keywords}

The six keywords exclusive to the high-performing automotive manufacturers in Figure 5 are society, electric, technology, standards, contribute, and global. The keywords were arranged in the same way among the high-performing automotive manufacturers [40]. Sample sentences that used these keywords included the following:

- " ".... well-being of the disadvantaged sections of society for sustained economic growth."

- "We will enhance the distinctive environmental technologies used in the plug-in hybrid electric vehicles...."

- " ".... electric based on the belief that environmental technology can contribute to society when they come into widespread use in the environmental fields."

- " “... reduce $\mathrm{CO}_{2}$ emissions in line with the Paris Climate Agreement and working with California for stronger vehicle greenhouse gas standards."

- "Vehicles equipped with e-POWER contribute to reducing $\mathrm{CO}_{2}$ emissions...."

- ".... global change, we will ensure that we achieve our sustainable growth into the future through our focus on the environmental, social, and governance (ESG) realm."

In summary, the associated environmental concepts of the high-performing automotive manufacturers are social contribution, eco-friendly technology, and standards for the company, and global changes.

The six keywords exclusive to the low-performing automotive manufacturers in Figure 5 are sales, target, promote, energy, efforts, and system. The keywords were arranged from the highest to the lowest quantitative value of eigenvector centrality in the same way [40]. Sample sentences that used these keywords included the following:

- "Sales in other regions fell to $¥ 481.5$ billion, down $7.1 \%$ from the previous year, reflecting a significant falloff in the number of pickup trucks shipped to ...."

- ".... promote the achievement of the annual business target through strengthening the sales system, optimizing the cost structure, improving the brand ...."

- " ".... we promote drastic reforms of our corporate structure, such as improved work efficiency through work style reforms including telework, maintain appropriate production and sales review investment and reduce fixed costs ...."

- " "... a decrease in new energy subsidies and other factors, passenger vehicle production and sales were continuously under pressure."

- " "... we must make efforts to improve the environmental performance of commercial vehicles."

- "During the year, TML successfully transitioned its entire product range to BSVI emission norms, with historically low levels of system inventory."

In summary, the associated environmental concepts of the low-performing automotive manufacturers are financial performance (sales, cost, production), environmental performance, efficiency (reforms of the corporate structure), and the role of governments (BSVI emission norms).

The results of the keyword analysis revealed significant differences between the high- and low-performing automotive manufacturers. The high-performing automotive manufacturers aimed to be leading companies that focused on the ESG realm. However, the low-performing automotive manufacturers did not focus on ESG. This suggests that the high-performing automotive manufacturers by car sales data mostly have the attributes of ESG.

\subsection{Keyword Trend Comparison}

The keywords extracted in this study were compared with those in previous studies conducted on the environment. The keywords of the upper group were selected and then compared with six keywords from each study. Six keywords (society, electric, technology, standards, contribute, and global) only were included for the upper group in this research.

Wang et al. [68] deduced the keywords on the energy and environment fields that had the highest frequency in publications. The keywords were retrieved from 1998 to 2016. In 
this study, as well as the previous study, the six keywords energy, GHG (greenhouse gas), LCA (life cycle assessment), industrial ecology, China, and international trade were considered important, and environmental keywords such as $\mathrm{CO}_{2}$ emissions, carbon footprint were excluded. Kuo et al. [69] derived management, supply chain, sustainable, production, performance, and model in that order from a literature review on the technologies involving eco-innovation.

Electric (=energy), technology $(=L C A)$, standards $(=G H G$, management), and global (=international trade) are classified as common keywords, and keywords with high importance show similar patterns. Therefore, the frequency of keywords derived as research topics and keywords considered necessary in actual CEO messages tend to be similar. This suggests that the environmental keywords viewed from the research point of view and the keywords that the CEO considers important—electricity, technology, standards, and global-are the most important keywords.

\subsection{Environmental Management Characteristics}

In the upper-group corporations, the characteristics (key factors) of the environmental management included normative pressures, technology, and environmental managerial concerns. Normative pressures are standards and regulations published by environmental agencies to meet the needs of public institutions, customers, suppliers, and society [34]. Structurally, they are closely linked to regulatory pressures, cooperation, and human resources. The key drivers of eco-innovation are environmental, social, or global standards (regulations) distributed by institutions.

Technology constitutes the technological and environmental characteristics of the industry, which are considered significant. Structurally, these are closely linked to the expanding market and cooperation. The automotive industry ecosystem is changing because of ecofriendly technologies (such as electric vehicles and fuel cell electric vehicles), mobility services, and purpose-built vehicles. Environmental managerial concerns denote the role of CEOs in achieving environmental management and innovation, which are also considered significant. Structurally, these are closely linked to environmental culture, human resources, and expanding market. The upper-group corporations showed high eigenvector centrality for factors such as technology, normative pressures, and environmental managerial concerns, indicating that their environmental management aimed to fulfill a mandate on ESG-environmental (=technology), social (=normative pressures), and governance (=environmental managerial concerns) performance. This suggests that the upper-group corporations have the attributes of good ESG performance and are already acknowledged in the market as sustainable companies.

\section{Conclusions}

\subsection{Proposals for CEO Messages}

This study has significance in comparing the environment-related keywords used by CEOs of upper- and lower-performing automotive companies and suggests the ecoinnovation key factors. Many researchers have analyzed the CEO messages of companies $[1,5,8]$. However, we found no cases in which the differences in CEO messages of the upper- and lower-performing automotive companies were analyzed. Therefore, the significance of this study is that it selected the subjects of analysis based on the car sales performance of the companies and analyzed the orientation of the automotive companies. The following proposals can be made based on the characteristics of environmental management identified by analyzing CEO messages.

First, the lower group needs to include and mention the keywords of the highperforming automotive manufacturers in their CEO messages. The keywords of the upper group were society, electric, technology, standards, contribute, and global. Second, the lower group should emphasize the factors of the upper group in their CEO messages. The eco-innovation factors of the upper and lower groups were different. For the upper group, technology, normative pressures, and environmental managerial concerns exhibited high centralities, whereas the lower group had high centralities for performance and the role of 
governments. Third, CEOs need to use the words that emphasize ESG performance in their CEO messages. Eco-innovation factors differed between the upper and lower groups, and the former placed more importance on environmental technology, normative pressures, and environmental managerial concerns from an ESG perspective. Hence, the CEO plays a vital role in eco-innovation, in which sustainability and innovation are integrated to successfully overcome corporate and normative challenges.

The need for ESG corporate strategies and performance evaluation is growing [15,70]. Thus, corporate CEOs need to respond to evaluations from an ESG point of view preemptively. It was found that the high-performing automotive manufacturers emphasized environmental keywords (such as society, electric, technology, standards, contribute, and global) and eco-innovation factors (such as technology, normative pressures, and environmental managerial concerns). Thus, CEOs of the lower group need to address these keywords and these key factors of the upper group in their CEO messages.

Due to environmental concerns, automotive companies must develop new technologies [20], and CEO communication of automotive manufacturers in the ESG area is important because concerns regarding ESG have spread throughout the entire value chain, affecting the environmental strategies of both suppliers and automotive companies [18]. Furthermore, it is notable that CEOs stress eco-friendly technologies (electric vehicles and fuel cell electric vehicles) can contribute to society. In particular, the word standards need to be used in relation to the regulations on $\mathrm{CO}_{2}$ emissions and global environmental standards $[16,21]$. Considering the $\mathrm{CO}_{2}$ emissions in the automotive industry, $\mathrm{CEO}$ must treat environmental concerns as important, highlighting the significance of eco-friendly technologies and expressing that they are a basic and core contribution to society.

As the automotive industry changes, it is important for top management to adopt environmental innovation and integrate corporate strategies to solve problems in each area of ESG (environmental, social, and governance) performance. The top three reasons for benchmarking were profitability, return on assets, and sales [71,72]. Benchmarking of the high-performing automotive manufacturers is necessary for low-performing automotive manufacturers to become top-performing companies. Moreover, consumers' attitudes change depending on whether firms are responsible environmentally and socially [73]. Therefore, low-performing automotive manufacturers can benchmark their environmental vision using the environmental management characteristics (key factors) of high-performing automotive manufacturers.

Exhaust gas regulation is a global trend and poses a very high risk to the automobile industry. If exhaust regulation requirements are not satisfied, the cost must be paid to the relevant government in proportion to the amount of emissions and sales, and the level may affect profits. Additionally, investment in new market creation is needed at a time when the paradigm of the automobile industry is changing from internal combustion engines to eco-friendly vehicles. In terms of industrial policy, the characteristics of environmental management of the high-performing automotive manufacturers are also important. In particular, early adoption of environmental regulations can affect the response of automotive manufacturers in developing eco-friendly vehicles [74]. For this reason, the comparison between high- and low-performing automotive manufacturers is significant from an ESG perspective.

At this moment, the lack of technology and supply of eco-friendly automotive parts causes high costs. So, price competitiveness is inevitable among manufacturers, which leads to a profitability deficit. Automotive manufacturers need to secure advanced technology such as batteries and motors, and incur enormous R\&D and investment costs. To solve insufficient supply, sales promotion is needed to create high demand and cost reduction through mass production. For this reason, there is a big barrier to entry for low-performing automotive manufacturers with insufficient profitability even with the current domination of internal combustion engines.

High-performing automotive manufacturers have greater advantages in responding to obstacles such as a lack of technology and sales than low-performing automotive man- 
ufacturers. Therefore, the results of this study confirm that more factors promoting ESG have been identified in high-performing automotive manufacturers. It is necessary for companies to invest in environmental vehicles, offer consumer incentives and promote development of a social norm encouraging the purchase of environmental vehicles [75]. Companies must emphasize the appeal of eco-friendly technologies and expand subsidies and infrastructure through cooperation with governments.

\subsection{Limitations and Future Plans}

An array of studies on ESG, with its ever-growing influence, should be conducted in the future. Dunbar et al. [31] found strong evidence that as a firm's CSR status improves (declines), which increases (decreases) its risk-taking capacity, the firm responds by adjusting compensation contracts to increase (decrease) CEO risk-taking incentives. A firm's ESG status can drive compensation contracts with CEO risk-taking incentives. Studying how a firm's ESG standing affects risk-taking incentives provided to a CEO through option-based compensation could be the first step of producing preliminary evidence on how managerial risk-taking incentives are established and adjusted. The results of such research should be of great interest to both business researchers and practitioners. The results of this study provide practical data for more effective environmental communication between CEOs and stakeholders. Furthermore, keywords of $\mathrm{CEO}$ communication may vary depending on the industry. Hence, an array of studies on CEO communication in industries not confined to the automotive sector should be conducted in the future.

This study did not reflect consistently high-ranking corporations in its data analysis. These companies could be considered to have already been performing sustainable management; thus, analyzing the $\mathrm{CEO}$ messages of this group may produce new insights. Moreover, differences among corporations across nations were not considered. Further research incorporating these factors will be useful to developing countries. This study did not sufficiently address the potential endogeneity issue and its remedies. For example, it did not consider that CEO communication to the public could reflect internal problems [76] within the enterprise or be driven by environmental management characteristics that cannot be observed. More robust results could be obtained if all of the above factors are considered.

Author Contributions: Conceptualization, Y.C.; methodology, Y.C.; software, Y.C.; validation, K.T.C.; formal analysis, Y.C.; writing-original draft preparation, Y.C.; writing-review and editing, Y.C. and K.T.C.; supervision, K.T.C. All authors have read and agreed to the published version of the manuscript.

Funding: This research received no external funding.

Institutional Review Board Statement: Not applicable.

Informed Consent Statement: Not applicable.

Conflicts of Interest: The authors have no conflict of interest to declare.

\section{References}

1. Ngai, C.S.-B.; Singh, R.G. Communication with stakeholders through corporate web sites: An exploratory study on the CEO messages of major corporations in Greater China. J. Bus. Tech. Commun. 2014, 28, 352-394. [CrossRef]

2. Choudhury, P.; Wang, D.; Carlson, N.A.; Khanna, T. Machine learning approaches to facial and text analysis: Discovering CEO oral communication styles. Strateg. Manag. J. 2019, 40, 1705-1732. [CrossRef]

3. Conte, F.; Siano, A.; Vollero, A. CEO communication: Engagement, longevity and founder centrality. Corp. Commun. Int. J. 2017, 22, 273-291. [CrossRef]

4. Kohut, G.F.; Segars, A.H. The president's letter to stockholders: An examination of corporate communication strategy. J. Bus. Commun. (1973) 1992, 29, 7-21. [CrossRef]

5. Oliver, S. Message from the CEO: A three-minute rule? Corp. Commun. Int. J. 2000, 5, 158-167. [CrossRef]

6. Bournois, F.; Point, S. A letter from the president: Seduction, charm and obfuscation in French CEO letters. J. Bus. Strategy 2006, 27, 46-55. [CrossRef] 
7. Bai, L.; Yan, X.; Yu, G. Impact of CEO media appearance on corporate performance in social media. N. Am. J. Econ. Financ. 2019, 50, 100996. [CrossRef]

8. Choi, Y.G.; Cho, K.T. Analysis of Safety Management Characteristics Using Network Analysis of CEO Messages in the Construction Industry. Sustainability 2020, 12, 5771. [CrossRef]

9. Chah, D.O. A study of recent research on CEO leadership. J. Organ. Manag. 2005, 29, 205-258.

10. Hambrick, D.C.; Fukutomi, G.D. The seasons of a CEO's tenure. Acad. Manag. Rev. 1991, 16, 719-742. [CrossRef]

11. Taliento, M.; Favino, C.; Netti, A. Impact of environmental, social, and governance information on economic performance: Evidence of a corporate 'sustainability advantage' from Europe. Sustainability 2019, 11, 1738. [CrossRef]

12. UNEP Finance Initiative. Show Me the Money: Linking Environmental, Social and Governance Issues to Company Value. Available online: https:/ / www.unepfi.org/publications/investment-publications/show-me-the-money-linking-environmentalsocial-and-governance-issues-to-company-value (accessed on 10 July 2021).

13. Lo, K.Y.; Kwan, C.L. The effect of environmental, social, governance and sustainability initiatives on stock value-Examining market response to initiatives undertaken by listed companies. Corp. Soc. Responsib. Environ. Manag. 2017, 24, 606-619. [CrossRef]

14. Cucari, N.; Esposito de Falco, S.; Orlando, B. Diversity of board of directors and environmental social governance: Evidence from Italian listed companies. Corp. Soc. Responsib. Environ. Manag. 2018, 25, 250-266. [CrossRef]

15. Berg, F.; Koelbel, J.F.; Rigobon, R. Aggregate Confusion: The Divergence of ESG Ratings, MIT Sloan School of Management. 2019. Available online: https:/ / papers.ssrn.com/sol3/papers.cfm?abstract_id=3438533 (accessed on 20 June 2021).

16. Lucarelli, C.; Mazzoli, C.; Rancan, M.; Severini, S. Classification of Sustainable Activities: EU Taxonomy and Scientific Literature. Sustainability 2020, 12, 6460. [CrossRef]

17. Park, H.J.; Kwon, I.S.; Shin, H.H.; Chung, J.W. The Relationship between Corporate Environmental and Financial Performance. Korean Manag. Rev. 2004, 33, 1461-1487.

18. Szász, L.; Csíki, O.; Rácz, B.-G. Sustainability management in the global automotive industry: A theoretical model and survey study. Int. J. Prod. Econ. 2021, 235, 108085. [CrossRef]

19. Díaz-Garrido, E.; Martín-Peña, M.L.; Sánchez-López, J.M. Determinants of environmental strategy in the automotive sector: Analysis of key factors. Int. J. Sustain. Transp. 2016, 10, 430-440. [CrossRef]

20. Park, E.-Y.; Yoon, H.-S.; Kim, T.-Y.; Oh, D.-R.; Cho, K.-T. An Empirical Analysis on the Patent Portfolio for Global Automotive Companies. J. Korea Technol. Innov. Soc. 2016, 19, 280-301.

21. Cho, S.H. A Few Thoughts on Changes in Automotive Industry and R\&D Strategy. Auto J. Korean Soc. Automot. Eng. 2020, $42,52-56$.

22. Yook, K. CEOs Talk about Social Responsibilities and Sustainable Performance: Applications of Text Mining Approach. Korea Acc. 2018, 27, 253-279. [CrossRef]

23. Na, H.J.; Lee, K.C.; Choi, S.U.; Kim, S.T. Exploring CEO Messages in Sustainability Management Reports: Applying Sentiment Mining and Sustainability Balanced Scorecard Methods. Sustainability 2020, 12, 590. [CrossRef]

24. Kim, S.; Lee, W.S. Network text analysis of medical tourism in newspapers using text mining: The South Korea case. Tour. Manag. Perspect. 2019, 31, 332-339. [CrossRef]

25. Xie, K.; Di Tosto, G.; Lu, L.; Cho, Y.S. Detecting leadership in peer-moderated online collaborative learning through text mining and social network analysis. Internet High. Educ. 2018, 38, 9-17. [CrossRef]

26. Ehrlich, K.; Lin, C.-Y.; Griffiths-Fisher, V. Searching for experts in the enterprise: Combining text and social network analysis. In Proceedings of the 2007 international ACM conference on Supporting group work, Sanibel Island, FL, USA, 4-7 November 2007; pp. 117-126.

27. Butts, C.T. Social network analysis: A methodological introduction. Asian J. Soc. Psychol. 2008, 11, 13-41. [CrossRef]

28. Drieger, P. Semantic Network Analysis as a Method for Visual Text Analytics. Proc. Soc. Behav. Sci. 2013, 79, 4-17. [CrossRef]

29. Marklines. Vehicle Sales Data. Available online: https:/ /www.marklines.com/en/vehicle_sales/search? mode=1 (accessed on 21 January 2021).

30. Laskin, A.V. The Narrative Strategies of Winners and Losers: Analyzing Annual Reports of Publicly Traded Corporations. Int. J. Bus. Commun. 2018, 55, 338-356. [CrossRef]

31. Dunbar, C.; Li, Z.; Shi, Y. CEO risk-taking incentives and corporate social responsibility. J. Corp. Financ. 2020, 64, 101714. [CrossRef]

32. Dunbar, C.G.; Li, Z.F.; Shi, Y. Corporate Social (IR) Responsibility and Firm Risk: The Role of Corporate Governance. Available online: https:/ / papers.ssrn.com/sol3/papers.cfm?abstract_id=3791594 (accessed on 28 August 2021).

33. Andries, P.; Stephan, U. Environmental Innovation and Firm Performance: How Firm Size and Motives Matter. Sustainability 2019, 11, 3585. [CrossRef]

34. Bossle, M.B.; Dutra de Barcellos, M.; Vieira, L.M.; Sauvée, L. The drivers for adoption of eco-innovation. J. Clean. Prod. 2016, 113, 861-872. [CrossRef]

35. Clatworthy, M.; Jones, M.J. The effect of thematic structure on the variability of annual report readability. Account. Audit. Account. J. 2001, 14, 311-326. [CrossRef]

36. Clatworthy, M.A.; Jones, M.J. Differential patterns of textual characteristics and company performance in the chairman's statement. Account. Audit. Account. J. 2006, 19, 493-511. [CrossRef] 
37. Hammami, H. Accounting narratives' characteristics and firm performance in the MD\&As of listed Italian companies. Int. J. Account. Financ. 2011, 3, 72-86.

38. Tambayong, L.; Carley, K.M. Network Text Analysis in Computer-Intensive Rapid Ethnography Retrieval: An Example from Political Networks of Sudan. J. Soc. Struct. 2012, 13, 1-24. [CrossRef]

39. Chung, C.J.; Park, H.W. Textual analysis of a political message: The inaugural addresses of two Korean presidents. Soc. Sci. Inf. 2010, 49, 215-239. [CrossRef]

40. Hong, J.H.; Yun, H.J. Presidential Candidate's Speech based on Network Analysis: Mainly on the Visibility of the Words and the Connectivity between the Words. J. Korea Contents Assoc. 2014, 14, 24-44. [CrossRef]

41. Nam, I.Y.; Park, H.W. Network Analysis of Headlines in the Newspaper Articles on the Prospective Presidential Candidates and their PR Strategy in Korea. Korean Party Stud. Rev. 2007, 6, 79-107.

42. Jung, Y. Semantic Network Analysis for the President Directions Item: Focusing on Paterns (2001 2009). J. Converg. Cult. Technol. (JCCT) 2018, 4, 129-137.

43. Cong, Y.; Freedman, M.; Park, J.D. Tone at the top: CEO environmental rhetoric and environmental performance. Adv. Account. 2014, 30, 322-327. [CrossRef]

44. Kang, M.S.; Choi, H.S.; Park, B.C. Effects of environmental management on firm performance. J. Korean Data Inf. Sci. Soc. 2011, 22, 523-536.

45. Hojnik, J.; Ruzzier, M. What drives eco-innovation? A review of an emerging literature. Environ. Innov. Soc. Transit. 2016, 19, 31-41. [CrossRef]

46. de Medeiros, J.F.; Ribeiro, J.L.D.; Cortimiglia, M.N. Success factors for environmentally sustainable product innovation: A systematic literature review. J. Clean. Prod. 2014, 65, 76-86. [CrossRef]

47. Kim, H.S. An Empirical Study on the Environmental and Financial Performance of Korean Firm's Environmental Management. Master's Thesis, University of Incheon, Incheon, Korea, 2006.

48. Brintrup, A.; Ledwoch, A.; Barros, J. Topological robustness of the global automotive industry. Logist. Res. 2015, 9, 1. [CrossRef]

49. Mäkelä, H.; Laine, M. A CEO with many messages: Comparing the ideological representations provided by different corporate reports. Account. Forum 2011, 35, 217-231. [CrossRef]

50. Barkemeyer, R.; Comyns, B.; Figge, F.; Napolitano, G. CEO statements in sustainability reports: Substantive information or background noise? Account. Forum 2014, 38, 241-257. [CrossRef]

51. Hahn, R.; Lülfs, R. Legitimizing Negative Aspects in GRI-Oriented Sustainability Reporting: A Qualitative Analysis of Corporate Disclosure Strategies. J. Bus. Ethics 2014, 123, 401-420. [CrossRef]

52. Opel. Sustainability. Available online: https://www.opel.ie/about-opel/sustainability/company.html (accessed on 10 July 2021).

53. Vauxhall. Sustainability. Available online: https://www.vauxhall.co.uk/about/sustainability/corporate-sustainability.html (accessed on 10 July 2021).

54. Kim, J.Y.; Kim, D.S. A Study on the Method for Extracting the Purpose-Specific Customized Information from Online Product Reviews based on Text Mining. J. Soc. E-Bus. Stud. 2016, 21, 151-161. [CrossRef]

55. Lee, S.S. A Content Analysis of Journal Articles Using the Language Network Analysis Methods. J. Korean Soc. Inf. Manag. 2014, 31, 49-68.

56. Lee, I.W.; Lee, Y.M. Semantic Network Analysis on Core Values and Policy Orientation: By Focusing on Moon Administration Policy Road-map. Korean Public Adm. Q. 2019, 31, 643-670. [CrossRef]

57. Choi, Y.G. Analysis of Safety Management Characteristics of Leading Construction Companies through Text Data Based Network Analysis. Ph.D. Thesis, Sungkyunkwan University, Suwon, Korea, 2021.

58. Hussain, S.; Muhammad, L.; Yakubu, A. Mining social media and DBpedia data using Gephi and R. J. Appl. Comput. Sci. Math. 2018, 12, 14-20. [CrossRef]

59. Freeman, L.C. Centrality in social networks conceptual clarification. Soc. Netw. 1978, 1, 215-239. [CrossRef]

60. Bonacich, P. Technique for Analyzing Overlapping Memberships. Sociol. Methodol. 1972, 4, 176-185. [CrossRef]

61. Kim, K.; Cho, K.T. A Review of Global Collaboration on COVID-19 Research during the Pandemic in 2020. Sustainability 2021, 13, 7618. [CrossRef]

62. Lee, K.M.; Hong, J.B. Case Study for Analysis of Technology Convergence Structure with Social Network Analysis. J. Technol. Innov. 2016, 24, 1-20. [CrossRef]

63. Valente, T.W.; Coronges, K.; Lakon, C.; Costenbader, E. How Correlated Are Network Centrality Measures? Connections 2008, $28,16-26$.

64. Howlader, P.; Sudeep, K.S. Degree centrality, eigenvector centrality and the relation between them in Twitter. In Proceedings of the 2016 IEEE International Conference on Recent Trends in Electronics, Information \& Communication Technology (RTEICT), Bangalore, India, 20-21 May 2016; pp. 678-682.

65. Liu, B.; Li, Z.; Chen, X.; Huang, Y.; Liu, X. Recognition and Vulnerability Analysis of Key Nodes in Power Grid Based on Complex Network Centrality. IEEE Trans. Circuits Syst. II Express Briefs 2018, 65, 346-350. [CrossRef]

66. Cherven, K. Mastering Gephi Network Visualization; Packt Publishing Ltd.: Birmingham, UK, 2015.

67. Ferns, B.; Emelianova, O.; Sethi, S.P. In His Own Words: The Effectiveness of CEO as Spokesperson on CSR-Sustainability Issues —Analysis of Data from the Sethi CSR Monitor@. Corp. Reput. Rev. 2008, 11, 116-129. [CrossRef] 
68. Wang, Y.; Li, J.; Lee, L.-C.; Wang, M.; Du, H. A review of input-output model application hot spots in the energy and environment fields based on co-words network analysis. Environ. Rev. 2019, 27, 567-574. [CrossRef]

69. Kuo, T.-C.; Smith, S. A systematic review of technologies involving eco-innovation for enterprises moving towards sustainability. J. Clean. Prod. 2018, 192, 207-220. [CrossRef]

70. Nirino, N.; Santoro, G.; Miglietta, N.; Quaglia, R. Corporate controversies and company's financial performance: Exploring the moderating role of ESG practices. Technol. Forecast. Soc. Chang. 2021, 162, 120341. [CrossRef]

71. Maiga, A.S.; Jacobs, F.A. The association between benchmarking and organizational performance: An empirical investigation. Manag. Financ. 2004, 30, 13-33. [CrossRef]

72. Cassell, C.; Nadin, S.; Older Gray, M. The use and effectiveness of benchmarking in SMEs. Benchmark. Int. J. 2001, 8, 212-222 [CrossRef]

73. Ciliberti, F.; Pontrandolfo, P.; Scozzi, B. Logistics social responsibility: Standard adoption and practices in Italian companies. Int. J. Prod. Econ. 2008, 113, 88-106. [CrossRef]

74. Rubio, F.; Llopis-Albert, C.; Valero, F.; Besa, A.J. Sustainability and optimization in the automotive sector for adaptation to government vehicle pollutant emission regulations. J. Bus. Res. 2020, 112, 561-566. [CrossRef]

75. Barth, M.; Jugert, P.; Fritsche, I. Still underdetected-Social norms and collective efficacy predict the acceptance of electric vehicles in Germany. Transp. Res. Part. F Traffic Psychol. Behav. 2016, 37, 64-77. [CrossRef]

76. Li, Z.F.; Liang, C.Y.; Tang, Z. CEO Social Media Presence and Insider Trading Behavior. Available online: https://papers.ssrn. com/sol3/papers.cfm?abstract_id=3532495 (accessed on 29 August 2021). 